\title{
Nonlinear Finite Element Analysis for Penstock Laid on Downstream Surface of Overfall Dam of Longtan Hydropower Station
}

\author{
Liu Keding \\ Hunan Urban Construction College \\ Xiangtan, China \\ 297298755@qq.com
}

\author{
Yang Zhichao \\ Yellow River Henan Bereau \\ Zhengzhou, China \\ yuluem@sina.com
}

\begin{abstract}
The numerical simulation study for water conveyance of penstock laid on downstream surface of overfall dam on water security is of great significance. Static analysis of penstock laid on downstream surface of overfall dam is the foundation of design and construction, includes the calculation and analysis of stress and strain of penstock laid on downstream surface of overfall dam. Using the nonlinear finite element theory and taking the penstock laid on downstream surface of overfall dam of Longtan Hydropower Station for the study,the inner surface of the cushion is defined as the goal face, using the outer surface of the steel liner tubet to the face contact and using the contact element to simulate the contact conditions between the steel liner pipe and the surrounding concrete at the same time we should take constitutive relations between the steel liner and concrete nonlinear into account and research the distribution of stress and deformation of the pressure pipe.
\end{abstract}

Keywords-Longtan hydropower station; Penstock laid on downstream surface of overfall dam, Nonlinear analysis; Finite element method; Static analysis.

\section{SUMMARY}

Longtan Hydropower Station is located in Tian'e County, Guangxi Province whose power installed capacity is 5.4 million $\mathrm{kW}$. Overflow Dam of hydropower diversion system uses a form of penstock and powerhouse is divided into two,with each underground powerhouse spillway plant containing 4 elements totally 9 elements, element capacity of 600MW. Plant normal water level is $400 \mathrm{~m}$. Water pipe maximum head is $202 \mathrm{~m}$ and the inner diameter of $9.5 \mathrm{~m}[1]$. Pipe wall thickness calculation section is $34 \mathrm{~mm}$, using steel of $16 \mathrm{MnR}$, elastic modulus $E_{s}=210 \mathrm{GPa}$,poisson's ratio $\mu=0.3$,yield strength $\sigma_{s}=330 \quad \mathrm{MPa}[2]$. Outsourcing between concrete strength grade uses C25.Steel pipe and the surrounding concrete initial gap is $0.5 \mathrm{~mm}$. Steel grade is II, with the tangent modulus of elasticity $E_{s}=200 \mathrm{GPa}$, Poisson's ratio $\mu=0.25$,yield strength $\sigma_{0.2}=310 \mathrm{MPa}$, secant modulus of elasticity $E_{c}=20 \mathrm{GPa}$, three-layer steel ring to the configuration, the inner reinforcement for $5 \times 2 \Phi 6$, the inner and outer layer of reinforced $5 \Phi 6$.

\section{CAlCulation MODEL}

\section{A Research Object}

Longtan hydropower diversion and power generation system with using steel lined reinforced concrete to penstock, we remove the tube back now (in the middle section of penstock pipe and ramp straight section).Typical pipe uses the three-dimensional nonlinear finite element analysis. During the analysis, wrapped in concrete thickness is calculated by $2 \mathrm{~m}$, selecting the domestic steel pipe of $16 \mathrm{MnR}$ and the plate thickness of $34 \mathrm{~mm}[3-4]$.

\section{B Model Element}

Nonlinear computational analysis of the outsourcing concrete uses the SOLID65 element, which is designed for concrete, rocks and other non-uniform materials whose feature is that compressive strength is much greater than the tensile strength[5-6]. SOLID65 element uses for the three-dimensional solid model with or without steel reinforcement. The solid model can have a crack and crush performance. In terms of the application of concrete,for example we use the solid performance element to simulate concrete and with adding the number of steels to simulate the effect of reinforced steel. Steel liner using SHELL63 element, SHELL63 both has the bending ability and also has a film strength, who can withstand a plane load and normal load[7-8].

\section{Concrete Model}

Elastoplastic constitutive relations used in the analysis to describe the concrete tensile stress - strain relationship uses Druker-Prager yield criterion[9]. Its plastic flow is associated flow, Concrete Compressive stress - strain relationship using the formula proposed by Saenz:

$$
\sigma=\frac{E_{0} \varepsilon}{1+\left(\frac{E_{0}}{E_{\varepsilon}}-2\right)\left(\frac{\varepsilon}{\varepsilon_{0}}\right)+\left(\frac{\varepsilon}{\varepsilon_{0}}\right)^{2}}
$$

Parameter Includes: $E_{0}$ is the initial elastic modulus. $E_{\varepsilon}=\sigma_{0} / \varepsilon_{0}$ is the secant modulus of elasticity of the stress reaches a peak. $\sigma_{0} 、 \varepsilon_{0}$ represent the stress and strain whose stress reaches the peak. 


\section{$D$}

Finite Element Model

When the finite element analysis of the penstock, we use the finite element method and we must

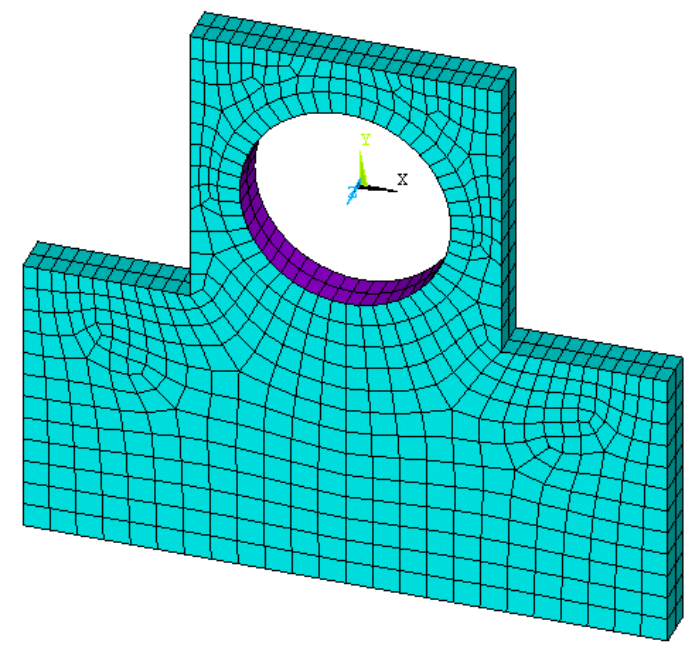

Figure 1. Finite Element partition diagram of penstock

\section{STRUCTURE ANALYSIS OF PENSTOCK}

\section{A Analysis Section}

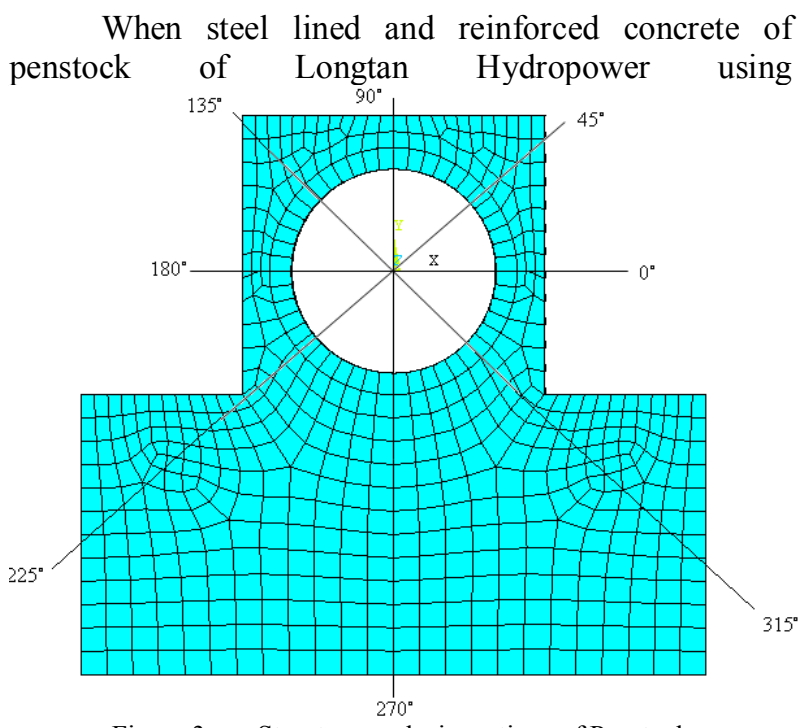

Figure 3. Structure analysis sections of Penstock

\section{B Cracking Process Analysis}

The results show that with the increase in the water pressure,the penstock gone through several stages as follows:

(1) $0 \leq P \leq 0.64 \mathrm{MPa}$, Since the radial steel liner deformation less than $2 \mathrm{~mm}$, without full contact between the steel liner and the surrounding concrete,internal water pressure to bear at this time there is a separate steel-lined, concrete pipe from power.

(2) $0.64<\mathrm{P}<1.0 \mathrm{MPa}$,Steel liner and concrete pipe began joint hosts, but the concrete is in the elastic state. first establish a finite element model of penstock[10]and the back pipe and structural finite element simulation range is divided as shown in Fig .1 and Fig .2.

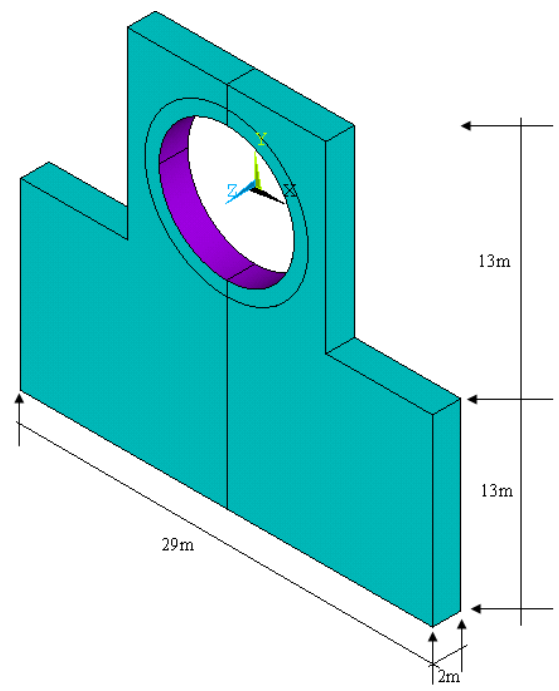

Figure 2. Model simulation range of penstock three-dimensional nonlinear finite element analysis, we remove the cross section shown analysis in Fig .3.

In this case, the local ring of concrete pipes to the maximum tensile stress occurs at about $\theta=45^{\circ}$ and $\theta=$ $135^{\circ}$, who located in the concrete edge of the inner tube.

(3) $1.0<\mathrm{P}<1.18 \mathrm{MPa}$,Outsourcing concrete localized plastic yield, the yield development from about $\theta=45^{\circ}$ and $\theta=135^{\circ}$ to the top of the pipe and the development from the inside edge to the outside edge of concrete.

(4) $\mathrm{P}=1.18 \mathrm{MPa}$,Outsourcing concrete floor cracks.

(5) $1.18<\mathrm{P}<1.4 \mathrm{MPa}$,Outsourcing concrete pipe cracks continue to increase

(6) $\mathrm{P}=1.64 \mathrm{MPa}$,Outsourcing concrete pipe cracks in the end.

Internal water pressure of penstock structure and the maximum radial displacement relationship is shown in Table 1.

As can be seen from Table 1, with the increase in the water pressure at the outer edge of the concrete pipe, maximum displacement gradually increased, and the increase at an increasing rate. This is due to the water pressure within hours when comparing, with not yet concrete pipe cracking, at the same time the deformation is relatively small.But when the internal pressure increases, the concrete pipe began to enter the plastic stage, and appeared cracks so that the deformation sharply increased. 
TABLE 1. THE MAXIMUM RADIAL DISPLACEMENT IN OUTER EDGE OF PENSTOCK

\begin{tabular}{|c|c|c|c|c|c|c|c|c|}
\hline $\begin{array}{c}\text { Internal water } \\
\text { pressure (MPa) }\end{array}$ & 0.64 & 0.94 & 1.18 & 1.40 & 1.64 & 2.14 & 2.64 & 3.64 \\
\hline $\begin{array}{c}\text { maximum } \\
\text { radial } \\
\text { displacement } \\
(\mathrm{mm})\end{array}$ & 0 & 0.788 & 0.825 & 1.27 & 1.617 & 2.518 & 3.162 & 4.824 \\
\hline
\end{tabular}

\section{Stress Analysis}

Within a given water pressure at the dam and the surrounding concrete penstock, the circumferential stress was shown in Fig .4 to Fig .7.

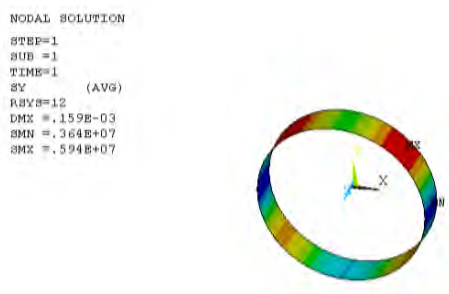

Figure 4. circumferential stress cloud of Steel liner (Internal pressure:0.94MPa)

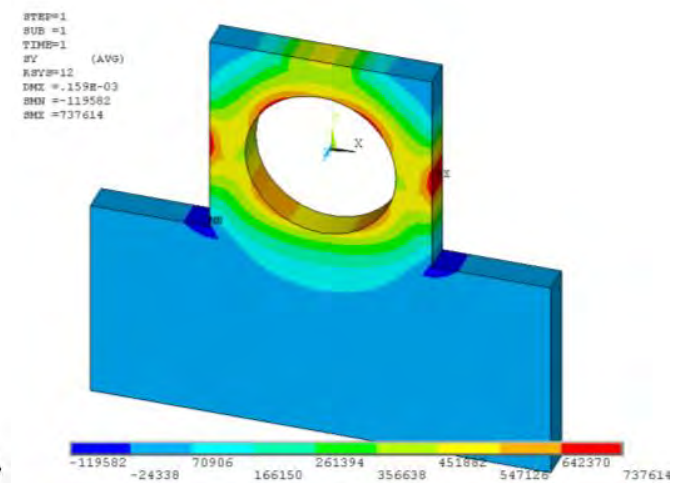

Figure 5. circumferential stress cloud of concrete (Internal pressure:0.94MPa)

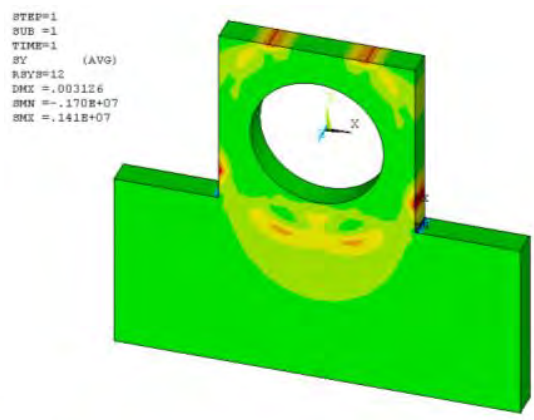

Figure 6.

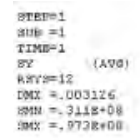

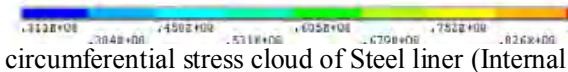
pressure:1.64MPa)
Figure 7. circumferential stress cloud of concrete (Internal pressure:1.64MPa)
As can be seen from Fig .4 to Fig .7, with the increase of the inner water pressure, the value of circumferential stress in the steel liner is gradually increased, the maximum stress on the surrounding concrete to extend outward from the inner surface, which is mainly due to cracking of the concrete as the inner stress is gradually released and the maximum stress gradually extended to the outer ring.

\section{CONCLUDING REMARKS}

In summary, penstock laid on downstream surface of overfall dam of longtan hydropower station has the reasonable design and penstock will not crack occurred in the design load so the structure meets the strength requirements.Because of the smaller tube deformation so that it can meet stiffness requirements. Structural design is economical, safe and reliable.

\section{REFERENCES}

[1] Wei Zhang, Hegao Wu. Study on safety performance of bearing capacity of penstock on downstream face of dam $[\mathrm{J}]$. Water resources and hydropower engineering, 2008,39(9):40-43.

[2] SL191-2008. Design Code for Hydraulic Concrete Structure[S] China Water Conservancy and Hydropower Press, 2008.

[3] Suohong Jiang. Application of the elasticity center method of structure mechanics for penstock laid on the downstream face of dam [J]. Water power, 2003,29(9):31-34.

[4] Min Xia. Research on the crack width formula of steel lined reinforced concrete penstock laid on downstream surface of dam [J]. Concrete, 2011,(9):36-39,43.

[5] Bofang Zhu. Finite Element Method Principle and Application [M]. China Water Conservancy and Hydropower Press, 1998. 
[6] Congbao Wang, Hegao Wu. Comparison Analysis of Elasticity Center Method and Finite Element Method for Penstock Laid on Downstream Surface of Dam [J]. Water resources and power, 2005,23(4):8-11.

[7] Xucheng Wang. Finite Element Method [M]. Tsinghua University Press, 2003
[8] Hegao Wu, Wei Zhang. Study on wall thickness of steel lined reinforced concrete penstock laid on downstream surface of dam [J]. Journal of hydraulic engineering, 2006, 37(9):1085-1091.

[9] Jianjing Jiang, Xinzheng Lu, Lieping Ye. Finite Element Analysis of Concrete Structures [M]. Tsinghua University Press, 2004.

[10] Jiaxuan Mai. Hydraulic Structures [M]. Tsinghua University Press, 2005. 